\title{
CHARACTERIZATION OF FATTY ACID METHYL ESTERS FROM OILS WITH DIFFERENT ORIGINS USING FOURIER TRANSFORM INFRARED SPECTROSCOPY
}

\author{
Krasimira Georgieva, Petko Petkov, Nikola Todorov \& Yordan Denev \\ "Prof. Assen Zlatarov" University of Burgas, Bulgaria \\ 1 Prof. Yakimov, 8010 Burgas, Bulgaria \\ e-mail: krasiianeva@yahoo.com
}

\begin{abstract}
The fatty acid methyl esters (FAME) of triglycerides obtained by transesterification reaction in the presence of alkaline catalysts became a serious alternative of fossil fuels. In the present research FAME synthesized from five different in their chemical nature and composition vegetable oils were studied. The data for analysis and characterization of FAME was obtained using fourier transform infrared spectroscopy and then basic properties of biodiesel fuels were determined. The confirmation and validation of the results were proved by classical chemical methods of analysis. The ability for express analysis of biodiesel fuels by IR spectroscopy was confirmed and the achieved results are reliable basis for the biofuels stability research.
\end{abstract}

Keywords: biodiesel; Fourier transform infrared spectroscopy; stability; properties.

\section{INTRODUCTION}

At present the demand for renewable energy sources to replace fossil fuels is partly a primary task in the world and became serious scientific interest [1]. The global energy crisis is the main motive for research of alternative energy sources along with pollution and negative environmental impact of petroleum fuels.

The biodiesel has many advantages compared to conventional fuels. Among the more important are their high fuel efficiency, low sulfur and aromatic content, higher cetane number, it is high biodegradable etc. [1]. Biodiesel is produced mainly by the transesterification process in which the oils react with alcohol in the presence of a catalyst [24]. During the reaction intermediate products as glycerol, mono-and diglycerides are obtained and small amounts of them can be found in the final product of biodiesel.

The study of the quality of biodiesel is a very important task for a several reasons. The first is because the determination of the chemical composition and physical properties of biodiesel is important because of the effects of transesterification conditions on the final product. The second main topic is blending of biodiesel with other, sometimes unknown products. The development of analytical methods for assessing contamination levels is necessary. The determination of the ratio of components in biodiesel mixtures represents a key task in his study and characterization [5].

Infrared spectroscopy uses energy region of the electromagnetic spectrum with wavelengths longer than visible light and shorter than radio waves [6].

The middle infrared region describes absorbance spectrum of all chemical bonds $\mathrm{O}-\mathrm{H}, \mathrm{N}-\mathrm{H}$, $\mathrm{C}=\mathrm{O}, \mathrm{C}-\mathrm{H}$ etc. The spectrum is sensitive to physical and chemical states of studied samples between 4000 and $400 \mathrm{~cm}^{-1}$. 


\section{ARTTLY $Y$}

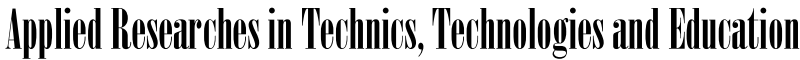

Journal of the Faculty of Technics and Technologies, Trakia University https://sites.google.com/a/trakia-uni.bg/artte/

Most often this area is widely used for analysis of biodiesel due to the presence of specific bands in the range $1500-800 \mathrm{~cm}^{-1}$, called the "fingerprint" region where absorbance include results from complex, intermolecular vibrations that gives unique information [7] .

The aim of present work is basic properties characterization of FAME (biodiesel) derived from vegetable oils by transesterification reactions in the presence of an alkaline catalyst and to determine the basic properties using infrared spectroscopy.

\section{METHODS}

In the reactor the amount of vegetable oil needed to obtain the desired mole ratio (from 5:1 to 9:1) methanol / vegetable oil is loaded. Then the equipment is placed in a bath at a constant temperature and heating at 25 to $45^{\circ} \mathrm{C}$. The catalyst $(0.4-2 \% \mathrm{KOH}$ in $100 \%$ vegetable oil) completely dissolved in methanol with stirring, and then the resulting solution is added to the reactor. Beginning of the reaction is reported with the addition of an alcoholic solution of the catalyst and continues for a time of 2 hours. The average speed of stirring is 600 rounds per minute. After completion of the reaction, the reaction mixture is transferred into a funnel, allowing glycerol to separate gravitically for 2-3 hours. After glycerol layer is separated, excess of methanol in phase with the methyl ester is removed by evaporation at $70{ }^{\circ} \mathrm{C}$. The fatty acid methyl esters (biodiesel) are washed twice with an aqueous solution of phosphoric acid (5\%) until a pure phase of esters. This procedure is suitable for a variation to obtain various types of biodiesel with a wide range of properties.

The infrared spectra of the vegetable oils were recorded with a Fourier transfrom infrared spectrometer, Bruker Tensor 27, interfaced to a personal computer operating under Windows-based software OPUS 6.5. All spectra were recorded from 4000 to $400 \mathrm{~cm}^{-1}$ with resolution better than $4 \mathrm{~cm}^{-1}$, co-adding 32 interferograms with frequency resolution better than $0.01 \mathrm{~cm}^{-1}$. A thin film of a small amount of each sample (approximately $2 \mu \mathrm{L}$ ) was deposited between two discs of $\mathrm{KBr}$ to avoiding the presence of air. The frequency of each band was obtained automatically using command of the instrumentation software OPUS 6.5. The association of bands to specific functional groups was made by comparison of the peak frequencies with literature data for vibrational mode in fats and oils [8].

For the principal component analysis was made using Minitab Software 16.0. Our worksheet consists initially of eight columns and five rows. Each column consists of the peak positions $\left(\mathrm{cm}^{-1}\right)$ that a specific peak appears. Each row corresponds to an individual spectrum.

\section{RESULTS AND DISCUSSION}

It is well known from literature that the ester content is extremely important because the general properties of biodiesel are determined by the properties of individual esters of fatty acids. Properties of individual esters are determined by the structural properties of the fatty acids and alcohol [9].

The infrared spectra of the studied methyl esters derived from different vegetable oils are shown on Figure 1.

The figure shows the primary spectra of studied biodiesel samples. The bands at $1200 \mathrm{~cm}^{-1}$ can be attributed to the axial deformation of the $\mathrm{CC}(=\mathrm{O})-\mathrm{O}$ bonds of esters, while the peaks around $1183 \mathrm{~cm}^{-1}$ may be associated with asymmetric axial deformation of the O-C-C bonds $[11,12]$. 


\section{IRTIL $<>$}

Ipplied Reseirl'ches in Technics, Technologies and Bducation Journal of the Faculty of Technics and Technologies, Trakia University https://sites.google.com/a/trakia-uni.bg/artte/

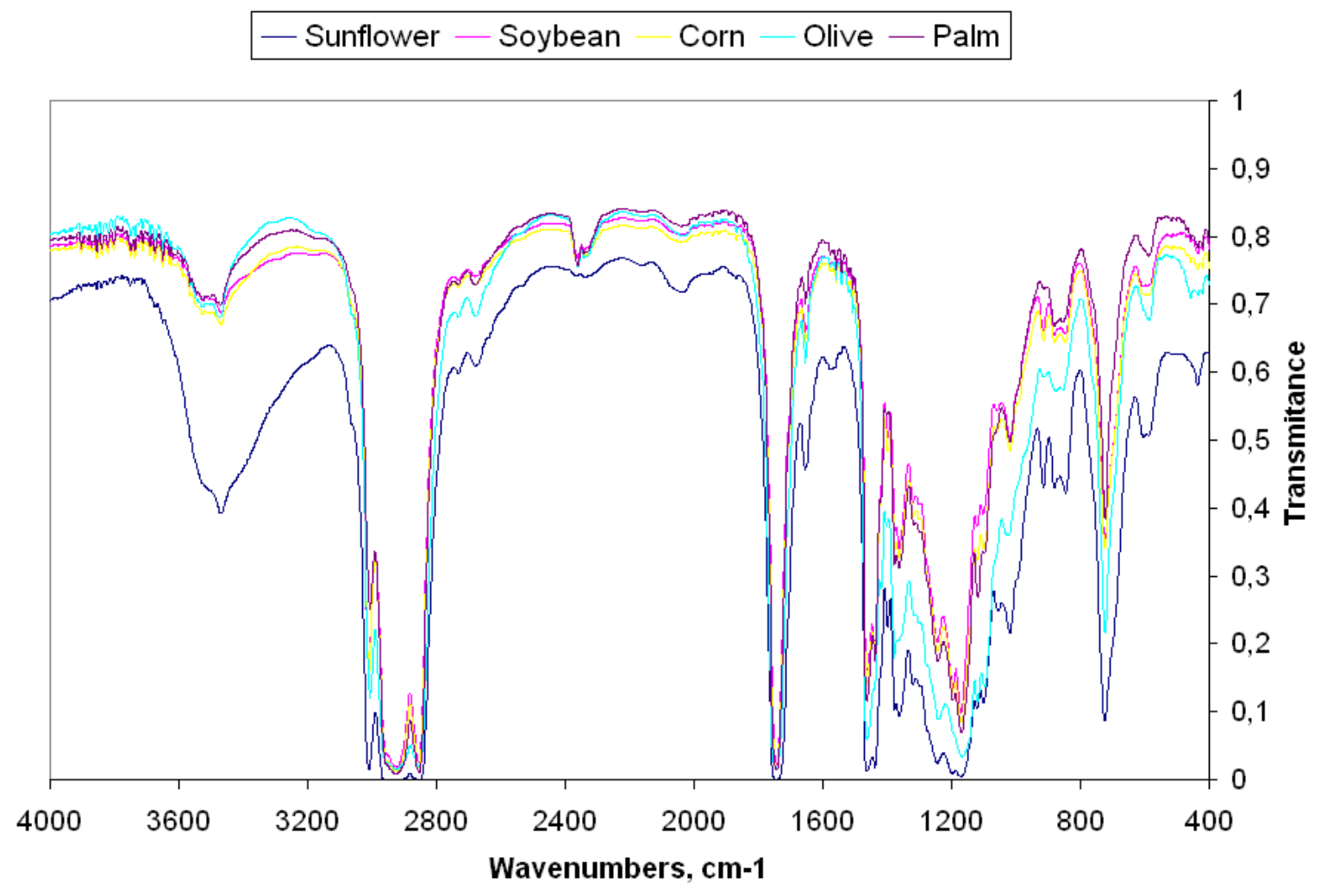

Figure 1. Infrared spectra of studied FAME

An important spectral region is located between 1735 and $1750 \mathrm{~cm}^{-1}$ where the absorption band corresponds to the vibrations of carbonyl groups of biodiesel. The end of the spectral region $\left(1750 \mathrm{~cm}^{-1}\right)$ usually prevails in the selection of variables to determine the parameters of oxidative stability. Variable at $1196 \mathrm{~cm}^{-1}$, which may be associated with asymmetric axial deformation of the O-C-C and other beach at $2900 \mathrm{~cm}^{-1}$ corresponds to $\mathrm{C}-\mathrm{H}$ link could also be selected.

The vibrations of the carbonyl group are also important in building a model for acid number. Also variables in the 2900 and $3000 \mathrm{~cm}^{-1}$ corresponding to the stretching of $\mathrm{C}-\mathrm{H}$ bonds of saturated carbon atoms [13] can be regarded as critical factors in the study of biodiesel.

Therefore, the variables selected using statistical methods included in the range of 1800 to $1600 \mathrm{~cm}^{-1}$ (carbonyl groups), but also in the region 1300-1000 $\mathrm{cm}^{-1}(\mathrm{C}-\mathrm{C}(=\mathrm{O})-\mathrm{O})$. The bands at $2900 \mathrm{~cm}^{-1}$, responsible for the $\mathrm{CH}$ stretching and bands at $725 \mathrm{~cm}^{-1}$ are associated with asymmetric angular deformation $(\mathrm{CH} 2) n$ chains.

In the case of using the PLS model variables that are associated with significant regression coefficients for that property includes the spectral region $3400-3600 \mathrm{~cm}^{-1}$, typical for the absorbance of water, which also showed positive results.

The spectra shown in Figure 1 clearly confirm the presence of a very intense peak at 1746 $\mathrm{cm}^{-1}$ which is caused by the vibration of $\mathrm{C}=\mathrm{O}$ group of the methyl esters. From literature it is known that there are many factors that influence the position of that band.

The main factors that affect the frequency of the $\mathrm{C}=\mathrm{O}$ group can be summarized as follows: factors that increase the $\mathrm{C}=\mathrm{O}$ frequency by electronegative replacing and lowering angle $\mathrm{C}$ $\mathrm{CO}-\mathrm{C}$; factors that lower $\mathrm{C}=\mathrm{O}$ frequency by conjugation and presence of hydrogen bonds. 


\section{IRT'TIE}

Ipplied Reseirl'ches in Technics, Technologies and Eduration

Journal of the Faculty of Technics and Technologies, Trakia University https://sites.google.com/a/trakia-uni.bg/artte/

Table 1. The frequencies and absorbance values of $\mathrm{C}=\mathrm{O}$ group in the studied FAME

\begin{tabular}{|l|c|c|}
\hline FAME & Frequency, $\mathrm{cm}^{-1}$ & Absorbance \\
\hline Corn & 1743.55 & 1.795 \\
\hline Olive & 1745.48 & 1.787 \\
\hline Sunflower & 1747.41 & 2.125 \\
\hline Palm & 1745.48 & 1.838 \\
\hline Soybean & 1743.55 & 1.648 \\
\hline
\end{tabular}

The principal components analysis (PCA) of the studied spectra was performed using eight characteristic bands for all methyl esters.

Table 2. Frequencies of the chosen bands used as variables in PCA

\begin{tabular}{|l|l|l|l|l|l|l|l|l|}
\hline FAME & Peak 1 & Peak 2 & Peak 3 & Peak 4 & Peak 5 & Peak 6 & Peak 7 & Peak 8 \\
\hline Corn & 1170.7 & 1195.8 & 1436.77 & 1463.89 & 1746.55 & 2854.48 & 2925.68 & 3008.78 \\
\hline Olive & 1166.7 & 1240.1 & 1419.53 & 1463.89 & 1745.48 & 2854.48 & 2925.84 & 3004.92 \\
\hline Palm & 1168.7 & 1242.0 & 1419.53 & 1463.88 & 1745.48 & 2854.48 & 2923.92 & 3006.85 \\
\hline Soybean & 1170.7 & 1195.8 & 1436.88 & 1463.89 & 1745.55 & 2854.48 & 2925.84 & 3008.78 \\
\hline Sunflower & 1170.7 & 1195.8 & 1436.88 & 1463.89 & 1747.41 & 2854.48 & 2921.99 & 3008.78 \\
\hline
\end{tabular}

Table 3. Results from PCA

\begin{tabular}{|l|l|l|l|l|l|l|l|l|}
\hline FAME & Peak 1 & Peak 2 & Peak 3 & Peak 4 & Peak 5 & Peak 6 & Peak 7 & Peak 8 \\
\hline Corn & 1170.7 & 1195.8 & 1436.88 & 1463.89 & 1746.55 & 2854.48 & 2925.68 & 3008.78 \\
\hline Olive & 1166.7 & 1240.1 & 1419.53 & 1463.89 & 1745.48 & 2854.48 & 2925.84 & 3004.92 \\
\hline Palm & 1168.7 & 1242.0 & 1419.53 & 1463.88 & 1745.48 & 2854.48 & 2923.92 & 3006.85 \\
\hline Soybean & 1170.7 & 1195.8 & 1436.88 & 1463.89 & 1745.55 & 2854.48 & 2925.84 & 3008.78 \\
\hline Sunflower & 1170.7 & 1195.8 & 1436.88 & 1463.89 & 1747.41 & 2854.48 & 2921.99 & 3008.78 \\
\hline
\end{tabular}

From the results obtained by using principal components analysis (PCA) can be clearly concluded that the bands that describe accurately the differences between the various methyl esters are at 1195,1436 and $1746 \mathrm{~cm}^{-1}$.

For characterization of the resulting methyl esters were calculated values for free fatty acids content using the following equation (1) [14]:

$$
F F A, \%=-0,044+4,9594 A+1,5446 A^{1 / 2}
$$

where FFA is free fatty acid content;

A is absorbance at $1711 \mathrm{~cm}^{-1}$.

The values obtained for the different origin FAME are summarized in table 4. From the data can be seen that the contents of free fatty acid changes in a relatively narrow range between 2.5 and 4.5 percent.

Table 4. Calculated values of free fatty acid content in the studied FAME

\begin{tabular}{|l|c|c|}
\hline FAME & Absorbance at $1711 \mathrm{~cm}^{-1}$ & Free fatty acids content, \% \\
\hline Corn & 0.3381 & 2.53 \\
\hline Olive & 0.4411 & 3.17 \\
\hline Sunflower & 0.3384 & 2.53 \\
\hline Palm & 0.3165 & 2.39 \\
\hline Soybean & 0.6995 & 4.71 \\
\hline
\end{tabular}




\section{IR'TIE}

Ipplied Resseirlohes in Technics, Technologies and Bducation

Journal of the Faculty of Technics and Technologies, Trakia University https://sites.google.com/a/trakia-uni.bg/artte/

On table 5 calculated values for trans-unsaturation of synthesized FAME are shown.

Table 5. Calculated values of trans- unsaturation of the studied FAME

\begin{tabular}{|l|c|c|}
\hline FAME & Absorbance at $966 \mathrm{~cm}^{-1}$ & trans- unsaturation, \% \\
\hline Corn & 0.2060 & 23.13 \\
\hline Olive & 0.3153 & 41.07 \\
\hline Sunflower & 0.1844 & 20.82 \\
\hline Palm & 0.1886 & 20.84 \\
\hline Soybean & 0.3766 & 45.52 \\
\hline
\end{tabular}

From the results presented in the table 5 clearly shows that the methyl esters with the highest trans-unsaturation are those derived from olive oil and sunflower oil, and the lowest from palm oil and soybean oil, and the differences in the two values is approximately two times. As a consequence of this fact can be expected and different relative stability of these esters and their mixtures with petroleum diesel.

\section{CONCLUSIONS}

The fatty acid methyl esters derived from five different in their chemical nature and composition vegetable oils were studied. The description of the differences in FAME was studied using principal component analysis. The bands at 1195, 1436 and $1746 \mathrm{~cm}^{-1}$ are determined as primary source for classification. The basic properties such free fatty acid content, trans-unsaturation and position of carbonyl group are calculated using data from infrared spectroscopy. These characteristics are very important in the biodiesel stability analysis.

The ability for express analysis of biodiesel fuels using fourier transform infrared spectroscopy was confirmed and the achieved results are reliable basis for the biofuels stability research.

\section{REFERENCES}

[1] Demirbas A. (2009). Progress and recent trends in biodiesel fuels. Energy Convers. Manage, Vol. 50, No. 1, (2009), p.14.

[2] Zagonel, G. F. \& Peralta-Zamora P. (2004). Multivariate monitoring of soybean oil ethanolysis by FTIR. Talanta, Vol. 63, No. 4, (2004), p.1021.

[3] Masato K. \& Hidaka J. (2012). Transesterification of vegetable oil into biodiesel catalyzed by CaO: A review. Fuel, Vol. 93, No.1 (2012).

[4] Thomasa T. P., Birneyb D. M. \&Auld D. L. (2013). Optimizing esterification of safflower, cottonseed, castor and used cottonseed oils. Ind. Crops Prod., Vol. 41, (2013), p.102.

[5] Knothe G. (2006) Analyzing biodiesel: standards and other methods. J. Am. Oil Chem. Soc., Vol. 83, No. 10, (2006), p.823.

[6] Smith B. (2011). Fundamentals of Fourier Transform Infrared Spectroscopy. CRC Press, New York, (2011).

[7] Lin M., Al-Koly M., Al-Quadirin H., Kang D.H., Cavinato A.G. \& Huang Y. (2004). Discrimination of intact and injured Listeria monocytogenes by Fourier Transform Infrared Spectroscopy and Principal Component Analysis. J. Agr. Food Chem., Vol. 52, No. 19, (2004), p. 5769.

[8] Safar M., Bertrand D., Robert P., Devaux M. F. \& Genot C. (1994). Characterization of edible oils, butters and margarines by Fourier transform infrared spectroscopy with attenuated total reflectance. J. Oil Fat Ind., Vol. 71, No. 4, (1994), p.371. 


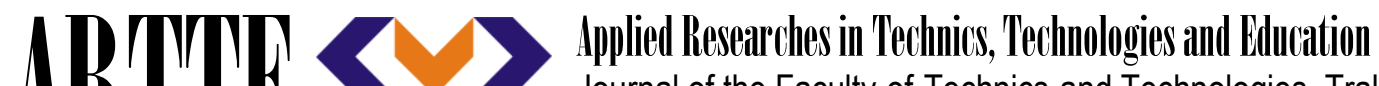 Journal of the Faculty of Technics and Technologies, Trakia University https://sites.google.com/a/trakia-uni.bg/artte/}

[9] Knothe G. Dependence of biodiesel fuel properties on the structure of fatty acid alkyl esters. Fuel Process. Technol., Vol. 86, No. 10, (2005), p. 1059.

[10] de Lira L.F.B., Souza de Albuquerque M., Pachero J.G.A., Fonseca T. M., Cavalcanti E., Stragevich L. \& Pimentel M. F.. Infrared spectroscopy and multivariate calibration to monitor stability quality parameters of biodiesel. Microchem. J., Vol. 96, (2010), p. 126.

[11] Pimentel M.F., Ribeiro G.M.G.S., Cruz R.S., Stragevich L., Filho J.G.A.P. \& Teixeira L.S.G. (2006). Determination of biodiesel content when blended with mineral diesel fuel using infrared spectroscopy and multivariate calibration. Microchem. J., Vol. 82, (2006), p. 201.

[12] de Lira L.F.B., de Vasconcelos F.V.C., Pereira C.F., Paim A.P.S., Stragevich L. \& Pimentel M.F. (2010). Prediction of properties of diesel/biodiesel blends by infrared spectroscopy and multivariate calibration. Fuel, Vol. 89, (2010), p. 405.

[13] Vasconcelos A.F.F., Dantas M.B., Filho M.G.R., Rosenhaim R., Cavalcanti E.H.S., Antoniosi Filho N.R., Sinfronio F.S.M., Santos I.M.G. \& Souza A.G. (2009). Influence of drying processes on oxidative stability of ethyl corn biodiesel by differentisl scanning calorimetry. J. Therm. Anal. Calorim., Vol. 97, (2009), p. 657.

[14] Ismail A.A., van der Voort F.R., Emo G. \& Sedman J. (1993). Rapid Quantitative Determination of Free Fatty Acids in Fats and Oils by Fourier Transform Infrared Spectroscopy. J. Am. Oil Chem. Soc., Vol. 70, No. 4, (1993), p. 335. 